\title{
Generative Design Approaches to Daylight in MURBs
}

\author{
Terri Peters ${ }^{1}$, Jake Wolf ${ }^{2}$, Brady Peters ${ }^{2}$ Ted Kesik $^{2}$ \\ ${ }^{1}$ Department of Architectural Science, Ryerson, Toronto, Canada \\ ${ }^{2}$ John H Daniels Faculty of Architecture, Landscape and Design, University of Toronto, Toronto, \\ Canada
}

\begin{abstract}
Access to acceptable levels of daylight are important for people's quality of life. Multi-unit residential buildings (MURBs) are known to perform poorly in terms of daylight compared to other residential building types. There are neither appropriate agreed upon metrics, nor effective methods for designing for daylight in MURBs. This paper presents results of a speculative design study that utilizes generative design to explore alternative geometries for the MURB tower typology. The experiment combines a genetic algorithm for spatial variation with climate-based daylight modeling (CBDM) to test the new forms against variations of the point tower MURB floorplan are commonly used. This paper identifies the poor performance of typical MURBs for daylight, and proposed new techniques for form generation. A new workflow has been developed and tested and a number of challenging issues have been identified.
\end{abstract}

\section{Introduction}

As the trend toward urban intensification continues in Canadian cities and around the world, a large number of existing and new housing are multi-unit residential buildings (MURBs) According to Canadian Census data, one third of new housing are MURBs and 1.9 million households live in this kind of housing (2016 Census). It is imperative that quality of life and inhabitant wellbeing be prioritized in this building type, as the compact footprint and repeated floorplate typical of MURBs pose challenges to attaining satisfactory levels of daylight and ventilation. MURB unit aspect ratios of 1:2 are not uncommon in current practice, which leads to suites that are deep with unacceptable levels of daylight (Peters and Kesik 2018). Numerous studies show daylight has a great impact on people's health and wellbeing (Veitch and Galasiu 2012) and daylight is central to architectural quality and desirability. Further studies are needed into performance based design exploration of formal and geometric options that maximize daylight. Many considerations drive MURBs design, but these are suspended in this study to isolate daylight as a design parameter.

MURBs design are not optimized for daylight, either in the building form or in the arrangement of individual units. MURB design tends to prioritize efficiency of repeating floorplates and developers seek financial gains for maximizing number of units and ease of construction. MURB research tends to focus on quantitative building performance aspects such as energy efficiency, ventilation and to a lesser extent daylight (Kesik and O'Brien 2017). This study is part of a larger ongoing study into daylight metrics, tools and design workflows in MURBs, and this sub-study offers a more speculative consideration of how generative design can facilitate daylight can be a design driver for new geometries and building forms in MURBs. This paper uses generative design to develop new geometries that privilege daylight, and climate-based daylight modeling (CBDM) to test the new forms against variations of the point tower MURB floorplan are commonly used. The aim is to propose and test new ways of working to compare options of MURB, and new design options for better daylighting (Figure 1). While daylighting was the primary consideration in the research underlying this paper, future studies will take a more robust generative design approach to consider additional factors to housing quality such as visual privacy, amenity such as terraces, green roofs and other considerations.

Generative design tools offer designers exciting possibilities in performance based design. There are few MURBs experiments event though new workflows are urgently needed to offer better quality of life. Some recent MURB examples were examined as inspiration for this paper, especially those with highly articulated facades that are designed for daylight. For example, 56 Leonard Street by Herzog and de Meuron is an irregular residential tower design in New York with a non-repeating floorplan and highly articulated and expressive façade. It serves as a formal inspiration to this research project offering an alternative tower aesthetic, although it is unclear if the façade design is performance driven. According to the architects, it was designed using formal strategies of staggering, setback and pixilation and it has been an architectural and commercial success (Herzog and de Meuron website). MVRDV's three story 'Valley' project in the Netherlands was a relevant precedent for this research in terms of design workflow and computational design. Designers at MVRDV were able to articulate and parametricize the project's design objectives and use a genetic algorithm to generate options in terms of daylight, views, structural design and code compliance (Christodoulou et al 2018). While the MVRDV project used multi-parameter optimization, this paper focuses on daylight. 


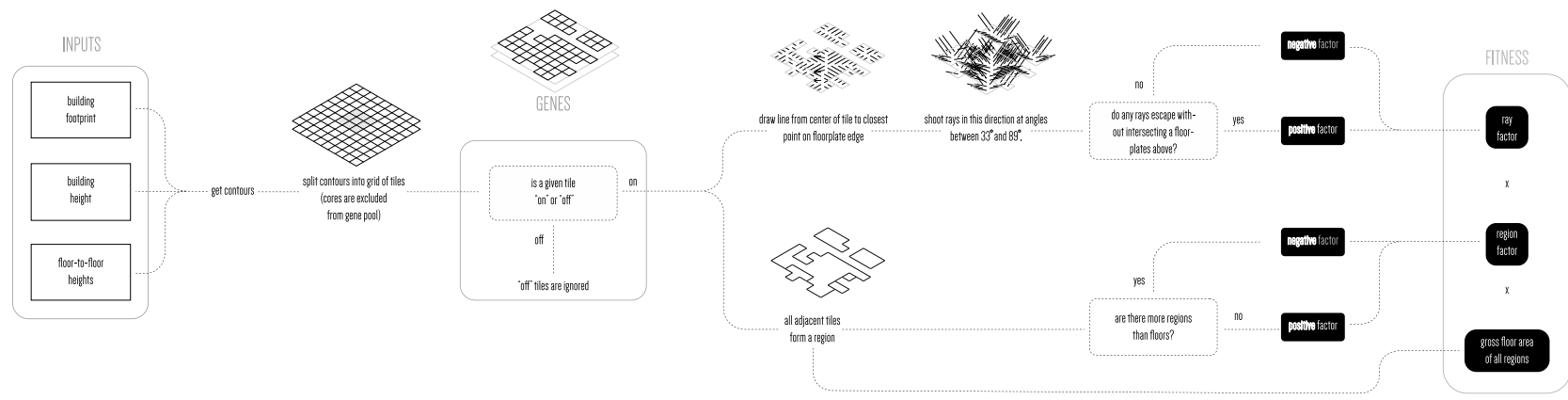

Figure 1: Generative Design Workflow.

\section{Methods}

This research uses two methods of performance-based design evaluation, first a genetic algorithm (Rutten 2013) and then climate based daylight modeling (CBDM) using DIVA-for-Rhino (Solemma 2016). Computational design was used and in particular a Genetic algorithm (GA) was developed because the design issues of form and daylight are complex, with potentially competing variables. The goal was to find solution "sets" of optimal design options rather that a singular solution. This allowed the setting of specific performance targets, and enabled the options to be optimized for very specific targets.
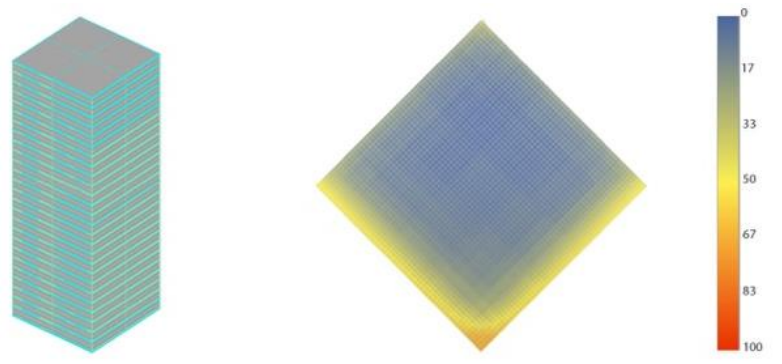

Figure 2: Isometric view of Point Tower 'base case' geometry and CBDM analysis of typical floor. Shown are the percentage of occupied hours that these nodes receive the target illuminance of 100 lux.

\section{Genetic Algorithm}

The initial design approach was to break up the building's floor-plates into modular 'tiles' for analysis and use a genetic algorithm to test a variety of combinations of these tiles based on daylight performance. With each arrangement of tiles, a new set of floor-plates is created and the entire building is re-tested for daylighting quality. Because the computational load of a full DIVA-for-Rhino for every design options was deemed not feasible, a proxy for daylighting quality was developed based on daylighting rules of thumb (Figure 3). These rules state that typically adequate daylight will penetrate 1.5 times the height of the window head (Reinhart, 2005). This basic rule of thumb does not consider the orientation of the building and so the algorithm does not either, the best performing options from this set of iterations are then tested in DIVA-for-Rhino.

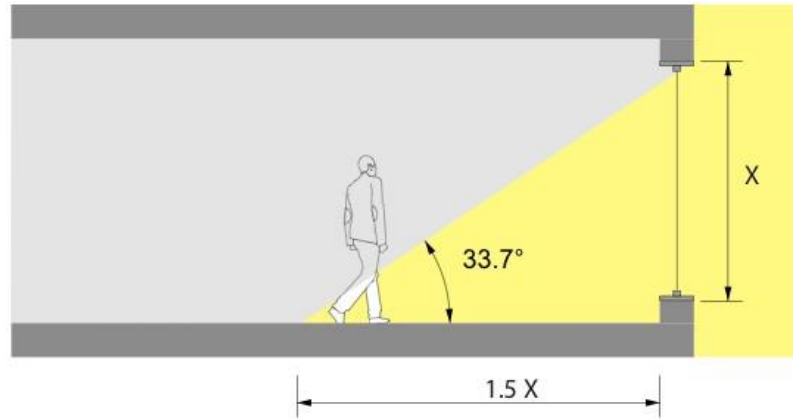

Figure 3: Daylight Rule of Thumb is typically measured as 1.5-2 times the head height of the window.

The study experimented with: the building footprint size and shape, number of storeys, floor-to-floor height and depth of the floor/ceiling structure. For this study, new options are compared to a 'base case', the point tower typology which is a typical MURB high-rise with a $27 \mathrm{~m}$ x $27 \mathrm{~m}$ footprint, that is 26 storeys tall, with $3 \mathrm{~m}$ external floor-to-floor height and $.5 \mathrm{~m}$ of structure between floors (figure 2). The relevant geometric parameters became inputs into the genetic algorithm, the floor area on each floor relate to a $3 \mathrm{~m} \times 3 \mathrm{~m}$ grid. Using Galapagos's Simulated Annealing algorithm, these grid tiles are either turned 'on' or 'off' (Rutten 2013). For each combination, all 'on' tiles are treated as a new floorplate. To determine the 'fitness' of each floor-plate a combination three factors are combined to provide an overall fitness value.

In using the parametric tool, the floorplate was arranged into zones for analysis. The $27 \mathrm{mx} 27 \mathrm{~m}$ floorplate was considered in three $9 \mathrm{mx} 9 \mathrm{~m}$ square zones which were then divided into smaller 'tiles' of $3 \mathrm{~m} \times 3 \mathrm{~m}$. The smallest unit of measure in the geometry studies was $3 \mathrm{~m}$ tiles are approximately the size of a room. The building cores for the stairs, elevators, and unit entry areas are simplified as the middle $9 \mathrm{mx} 9 \mathrm{~m}$ zone of the building. In this study, the cores are considered a low priority for daylight to prioritize daylight in the principle rooms of the dwellings. A genetic algorithm was used three ways to evaluate the performance of the design options. A light ray factor is achieved by arraying each floor-plate with points, and from each point rays are cast at an angle of 33.69 degrees (which corresponds to the daylight rule of thumb) toward 
the exterior of the building. The ratio of the rays cast to the rays which escape (i.e. those that do not intersect a ceiling above) provides a percentage of rays that hit the sky. A perfect score would be 1, meaning all tiles have light access. However, if this were the only driving factor the algorithm would find a solution in which most tiles are 'off', leaving the few remaining tiles with lots of access to light but creating a building with almost no occupiable space. The second evaluation metric, the GFA factor is indexed to the floor area. This is the ratio of the ground floor area (GFA) of the generated floorplates to the possible GFA (i.e. if all tiles were 'on'). Lastly, as a way to encourage the algorithm to seek tile combinations that make continuous floor-plates (i.e. not an archipelago of floor regions) the region factor acts as a penalty for each region beyond the minimum (in this case 26 regions, one for each floor).

\section{Daylight Modeling}

DIVA-for-Rhino was used to evaluate the best versions of four studied options generated by the GA. In order to test the best case scenarios, the window to wall ratio was set at $100 \%$ WWR to test all possible daylight availability, the building is positioned on a 45 degree angle facing South-East/South-West and internal partition walls are not considered. Vancouver was used as the building location and surrounding buildings and site context were not considered. This study assumed the buildings is occupied 8am-6pm with Daylight Savings Time (DSTI) invoked, analyzed in 60 minute increments. This is a typical occupancy schedule for daylighting, although some studies are challenging these assumptions in residential applications (Dogan and Park 2017). For the analysis grid, the node height and spacing assumptions are $0.5 \mathrm{~m}$ high, the node spacing is $0.5 \mathrm{~m}$ apart. This gives a relatively human scale proportion for the unit of measure when compared to the dwelling-scale measure used in the geometry study. The target illuminance threshold for measuring two similar dynamic daylight metrics: spatial daylight autonomy (sDA) was tested and the mean spatial daylight autonomy was also calculated (Illuminating Engineering Society of North America, 2012).

There are a number of daylighting performance metrics (DPM) used to quantity natural light and its availability including glare, aesthetics and non-visual effects of daylight. These metrics are not developed for use in MURB, and normally focus on performance issues facing workplace and office buildings (Dogan and Park 2018) which are not suitable for MURB. This study uses Spatial Daylight Autonomy (sDA) a commonly used annual daylighting metric that is more relevant than other options, such as Daylight Factor, for analysis of MURB. DA refers how much of the interior area (in this case the sensors were set at 0.5 high) receives a target daylight illuminance (often set to 300 lux in office settings, in this case 100 lux was used) at least $50 \%$ of the occupied hours. Mean Spatial Daylight Autonomy (Mean sDA) is the percentage of annual daytime hours that a floorplate's daylight levels are above a specified illumination level (IESNA 2012). Mean DA was found to be more of a relevant dynamic daylight metric to compare and interpret the performance of the different floorplans.

Table 1: Surface reflectance and glass transmittance used in the DIVA simulations.

\begin{tabular}{|c|c|}
\hline Material & $\begin{array}{c}\text { Reflectance/ } \\
\text { Transmittance }\end{array}$ \\
\hline Ceiling & $70 \%$ \\
\hline Floor & $20 \%$ \\
\hline Internal Walls & $70 \%$ \\
\hline $\begin{array}{c}\text { Façade Spandrel } \\
\text { Panel }\end{array}$ & $35 \%$ \\
\hline Façade Glazing & $65 \%$ \\
\hline
\end{tabular}

\section{Results}

Four series of design experiments were carried out and compared to an analysis of the base case MURB (figure 1 ). The point tower base case MURB has low levels of spatial daylight autonomy (DA100lux [50\%]=2\%) and low mean spatial daylight autonomy (15\%) on all floors.

\section{Point Tower- Articulated Floorplates}

Option A1 generated options that added articulation to the floorplates by creating unique floorplates that removes tiles that do not receive daylight, and relates to surrounding floors. When a floor tile is generated, a ceiling tile is added so each floor remains only one storey tall. The ceiling tiles block daylight rays so options are generated that optimize for the best performance for the overall building form. In some cases, the floorplates have large balconies, and often there are internal courtyards.

The highest performing floor is the top level, floor 26 . The spatial daylight autonomy is $9 \%$ (compared to base case of $2 \%$ ) and the mean spatial daylight autonomy is $28 \%$, (base case is 15\%). This floorplan arrangement of offers a number of unusual spatial relationships for MURB. There are large ( $3 \mathrm{~m} \times 3 \mathrm{~m}$ minimum) outdoor balconies with views down multiple levels into the building next to the core, bringing daylight into the core and heightening the sense of being at the top of the building. As with 76 Leonard Street, parts of the floorplan and in some cases the units could be geometrically distinct from one other, there could be a sense of being in a separate house, with different visual and acoustic relationships from the neighbours.

Floor 9 is also one of the highest performing floorplates (Figure 4). The algorithm generated this arrangement to allow light to come in from the sides, adding articulation to the floorplate and the overall building form. The arrangement of spaces is highly unusual for MURB, with spatial complexity despite the unit being arranged over one level. There are balconies with views to the sky as the next floor is five stories above, and internal courtyards where there can be indoor-outdoor views into the rooms. The daylight is improved and there would be cross ventilation, large outdoor areas and increased views to the sky inside the principle rooms. The spatial daylight autonomy is $8 \%$ (compared to base case of $2 \%$ ) and the mean spatial daylight autonomy is $27 \%$, (base case is $15 \%)$. 


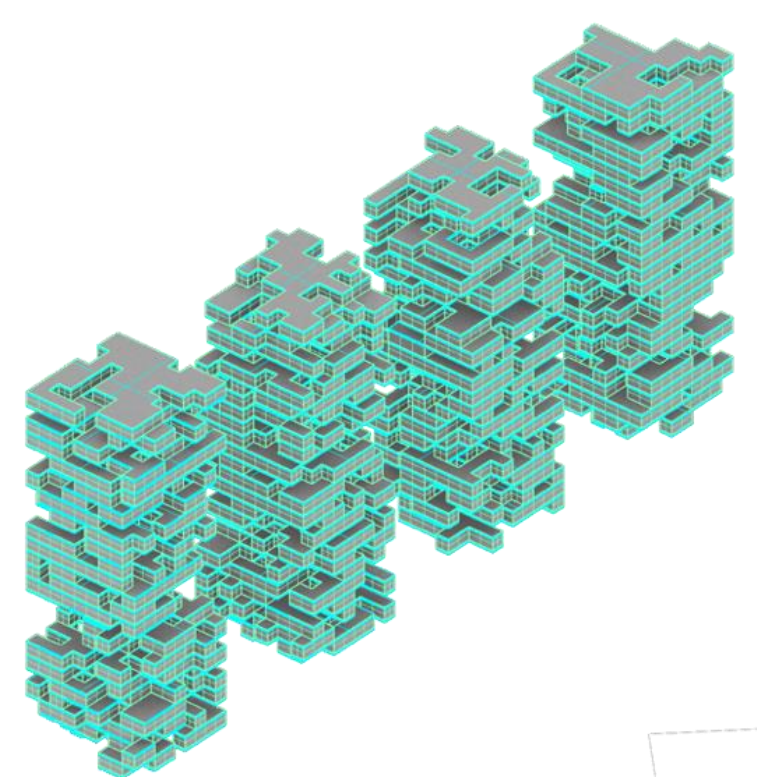

Figure 4: Option A1 Series. The four best optimized versions of this series.
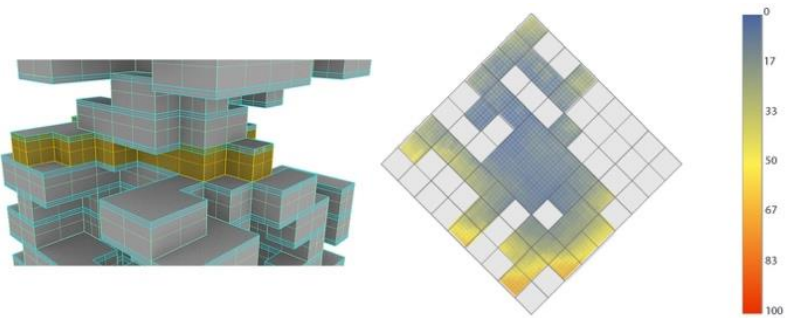

Figure 5: Detail of the building geometry of Option A1-1 highlighting Floor 9, and the CBDM unit analysis of Floor 16 using DIVA-for-Rhino. The analysis shows percentage of occupied hours that these nodes receive the target illuminance of 100 lux.

In terms of spatial daylight autonomy six of the floorplates equal the spatial daylight autonomy target of $2 \%$ as in the base case, six perform less well in terms of DA but better in mean DA, and fourteen exceed the base case with the highest being $9 \%$. Reflecting on results of Option A1 and the testing of version 1, the limitation of keeping each unit a single floor height was determined to be restrictive, and Option A2 explores the potentials of generating double height spaces.

Table 2: Option Al Version 1 DIVA results

\begin{tabular}{|l|l|l|l|l|l|}
\hline Floor & DA100lux[50\%] & Mean DA & Floor & DA100lux[50\%] & Mean DA \\
\hline 1 & $2 \%$ & $17 \%$ & 14 & $2 \%$ & $17 \%$ \\
\hline 2 & $2 \%$ & $16 \%$ & 15 & $1 \%$ & $16 \%$ \\
\hline 3 & $4 \%$ & $19 \%$ & 16 & $5 \%$ & $20 \%$ \\
\hline 4 & $3 \%$ & $17 \%$ & 17 & $4 \%$ & $17 \%$ \\
\hline 5 & $3 \%$ & $23 \%$ & 18 & $4 \%$ & $20 \%$ \\
\hline 6 & $4 \%$ & $22 \%$ & 19 & $2 \%$ & $15 \%$ \\
\hline 7 & $1 \%$ & $19 \%$ & 20 & $3 \%$ & $20 \%$ \\
\hline 8 & $7 \%$ & $26 \%$ & 21 & $0 \%$ & $10 \%$ \\
\hline 9 & $8 \%$ & $27 \%$ & 22 & $6 \%$ & $18 \%$ \\
\hline 10 & $4 \%$ & $25 \%$ & 23 & $2 \%$ & $19 \%$ \\
\hline 11 & $0 \%$ & $12 \%$ & 24 & $3 \%$ & $17 \%$ \\
\hline 12 & $5 \%$ & $19 \%$ & 25 & $2 \%$ & $15 \%$ \\
\hline 13 & $1 \%$ & $15 \%$ & 26 & $9 \%$ & $28 \%$ \\
\hline
\end{tabular}

\section{Point Tower- Double Height Spaces}

Option A2 improves upon Option A1 by improving daylight by generating double height spaces. The top four versions of a number of generate versions in this Option study are shown in image $X$. The algorithm generated options based on rules that dictated that when a floor tile does not have a corresponding tile above, a double-height space is created and a ceiling tile is added two floors above. Option A2 produced a wider range of performance than A1. In terms of spatial daylight autonomy, two of the floorplates equal the spatial daylight autonomy target of $2 \%$ as in the base case, eleven perform less well in terms of DA but better in mean DA, and thirteen exceed the base case with the highest at $16 \%$.

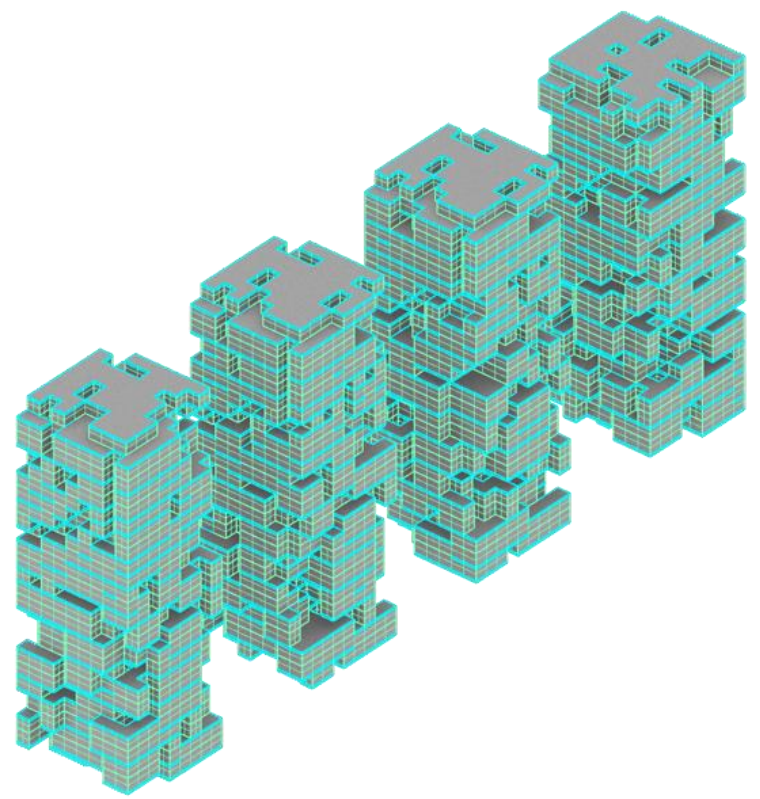

Figure 6: Option A2 Series. The four best optimized versions.
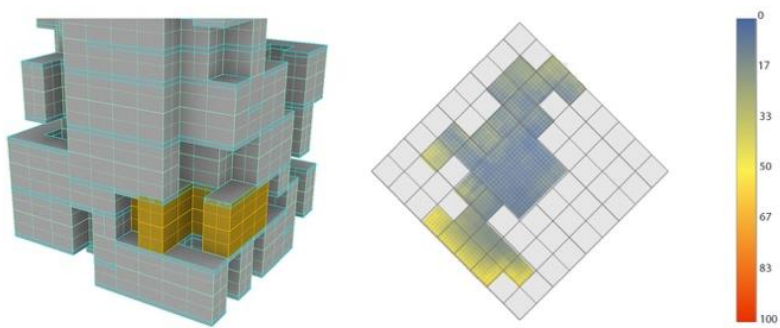

Figure 7: Detail of the building geometry of Option A2-1 highlighting Floor 3, and the CBDM unit analysis of

Floor 9 using DIVA-for-Rhino. The analysis shows percentage of occupied hours that these nodes receive the target illuminance of 100 lux.

Some of the results are impacted by the different floor areas generated per floor and the corresponding daylight performance. For example, floor 3 is the highest performing at $16 \% \mathrm{DA}$. This floorplate is small as it is generated by accommodating many double height spaces on the first floor. The entire floorplate of Level 3 is only $198 \mathrm{~m} 2$ (2131 sqft) including the core zone, so there will be fewer units. These units would arguably be very high quality and higher value, as their views into neighbouring 
suites on the floor would be at the double height part of that suite, so there would be increased privacy between neighbours. The dwellings on level 3 would enjoy the highest level of spatial daylight autonomy, double height spaces and terraces with four story high views to the sky. Level 3 is also clearly distinguishable as an architectural feature on the building's façade from street level, making it unique and potentially more desirable.

Table 3: Option A2 Version 1 DIVA results.

\begin{tabular}{|l|l|l|l|l|l|}
\hline Floor & DA100lux[50\%] & Mean DA & Floor & DA100lux[50\%] & Mean DA \\
\hline 1 & $7 \%$ & $24 \%$ & 14 & $1 \%$ & $17 \%$ \\
\hline 2 & $0 \%$ & $21 \%$ & 15 & $0 \%$ & $16 \%$ \\
\hline 3 & $16 \%$ & $24 \%$ & 16 & $4 \%$ & $20 \%$ \\
\hline 4 & $0 \%$ & $18 \%$ & 17 & $4 \%$ & $20 \%$ \\
\hline 5 & $4 \%$ & $24 \%$ & 18 & $0 \%$ & $15 \%$ \\
\hline 6 & $0 \%$ & $9 \%$ & 19 & $1 \%$ & $21 \%$ \\
\hline 7 & $7 \%$ & $28 \%$ & 20 & $11 \%$ & $23 \%$ \\
\hline 8 & $0 \%$ & $14 \%$ & 21 & $0 \%$ & $12 \%$ \\
\hline 9 & $1 \%$ & $18 \%$ & 22 & $10 \%$ & $23 \%$ \\
\hline 10 & $2 \%$ & $23 \%$ & 23 & $1 \%$ & $16 \%$ \\
\hline 11 & $6 \%$ & $21 \%$ & 24 & $10 \%$ & $25 \%$ \\
\hline 12 & $0 \%$ & $17 \%$ & 25 & $2 \%$ & $15 \%$ \\
\hline 13 & $5 \%$ & $14 \%$ & 26 & $5 \%$ & $25 \%$ \\
\hline
\end{tabular}

Reflecting on results of Option A2 and the testing of version 1, the double height spaces do as expected bring in more daylight and the decision to limit the height to two levels seems appropriate. The wide variety of performance was unexpected, and many floorplates performed better, but many also much worse than expected. This Option could use further refining, and a follow up study will add in the parameter of minimum floor area per floor in order to create more usable results. However, care would need to be taken to test different weightings of the floor area parameter because if a specific minimum or maximum floor area rule was incorporated then it would significantly lower the number of generated options. This could potentially weaken the overall findings of generating options designed for achieving daylit interior spaces, as it could shift the focus to floorplates that maximize quantity of interior floor area

\section{Point Tower- Complexity}

The starting point for the Option B1 series was the $27 \mathrm{mx}$ $27 \mathrm{~m}$ point tower, but the goal was to create more articulated and high-performance floorplate geometries, with a repeated single level floorplan. Option-B1 generates options that are based on the rule that when a tile on one floorplate does not have a corresponding tile above, a 'ceiling' tile is added so each floor is only one storey tall. Option B1-1 was the best performing version and it has large balconies and internal courtyards. The higher floors are slightly better performing than the lower levels. All of the floors perform better than the point tower base case examined in Option A1 and A2. The very articulated forms look similar to another typical MURB typology, the 'barbell' shape, or H-shape tower. For comparison, a typical H-shape tower was analyzed (see figure $\mathrm{X}$ ). The H-shape tower is a relevant 'base case' for Options B1 and Options B2. The H-shape base case MURB has higher levels of spatial daylight autonomy than the point tower base case, (DA100lux [50\%]=3\% and
$4 \%$ on level 26) and higher mean spatial daylight autonomy (17\% and $19 \%$ on level 26). Option B1-1 did not perform significantly higher than the $\mathrm{H}$-shape base case see Table 4 below. It is surprising that the B1 Options did not greatly improve in terms of daylight. Given the nature of the GA, it was expected that the GA should have found options that were more close to the $\mathrm{H}$ shape if it is in fact higher performing. There could be a number of reasons for this, including limitations in the GA fitness functions.
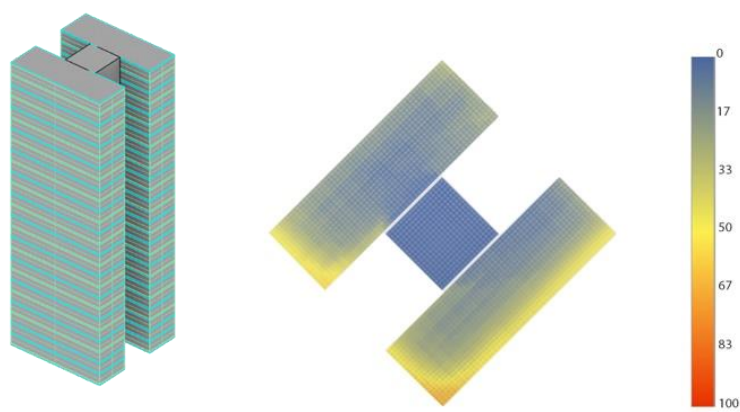

Figure 8: The geometry and typical unit analysis of the commonly used MURB geometry, the H-Shape Building using DIVA-for-Rhino. The analysis shows percentage of occupied hours that these nodes receive the target illuminance of 100 lux.
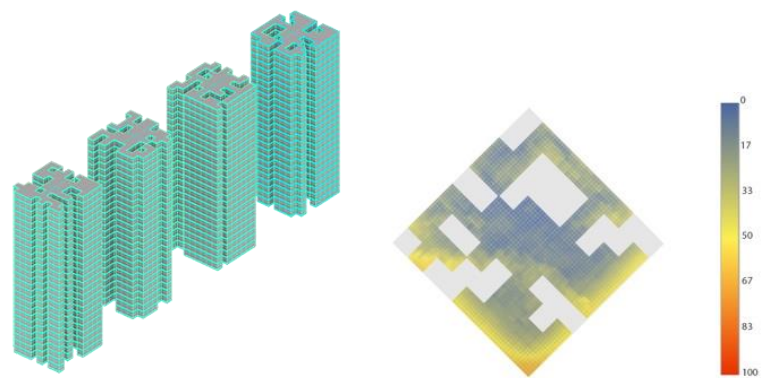

Figure 9: Option B1 Series. The four best optimized versions and a unit analysis of Floor 24 using DIVA-forRhino. The analysis shows percentage of occupied hours that these nodes receive the target illuminance of 100 lux.

Table 4: Option B1 Version 1 DIVA results.

\begin{tabular}{|l|l|l|}
\hline Floor & DA100lux[50\%] & Mean DA \\
\hline $1-21$ & $3 \%$ & $20 \%$ \\
\hline $22-23$ & $3 \%$ & $21 \%$ \\
\hline 24 & $4 \%$ & $22 \%$ \\
\hline 25 & $5 \%$ & $25 \%$ \\
\hline 26 & $9 \%$ & $32 \%$ \\
\hline
\end{tabular}

\section{Point Tower- Complexity}

Option-B2 generated sets of two floorplates, and these pairs are repeated 13 times. When a tile on the bottom floor-plate does not have a corresponding tile above, a double-height space is created and a ceiling tile is added two floors above. In the most optimized option, B2-1, the double height space has only one double height space, a 
single tile adjacent to the core. B2-2, B2-3 and B2-4 have more double height spaces. The set of alternating large and small floorplates could be imagined as potentially an open and daylit garden level and a more enclosed area. The 'floating' terraces on odd floors are disconnected from the floorplate, but these could be connected and be useful and unusual outdoor space. In this option, the floor plate has the core exposed in areas so it is daylit in areas. The forms generated are interesting form a privacy perspective, as the B2-1 option is broken into four distinct stacked 'buildings'. With so much outdoor space shown, it is clear that the north facing decks would be less useful. A future study could then maximize the large outdoor decks based on daylight to gain better performance on smaller floorplates
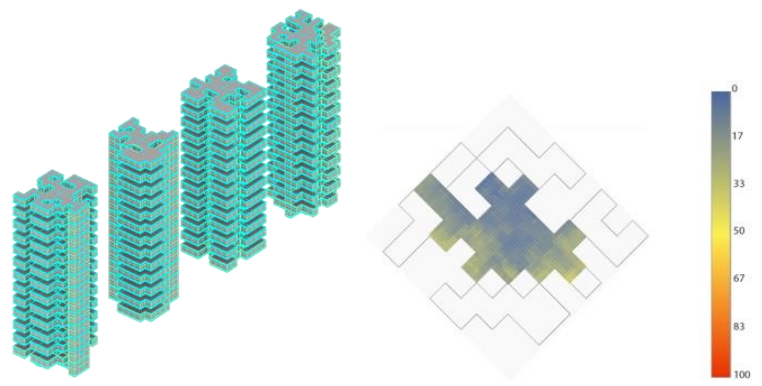

Figure 10: Four Options B2 Series. The four best optimized versions. B2-1 Floor 8 and Floor 9 SouthEast/South-West facing unit analysis using DIVA-forRhino. The analysis shows percentage of occupied hours that these nodes receive the target illuminance of 100 lux.
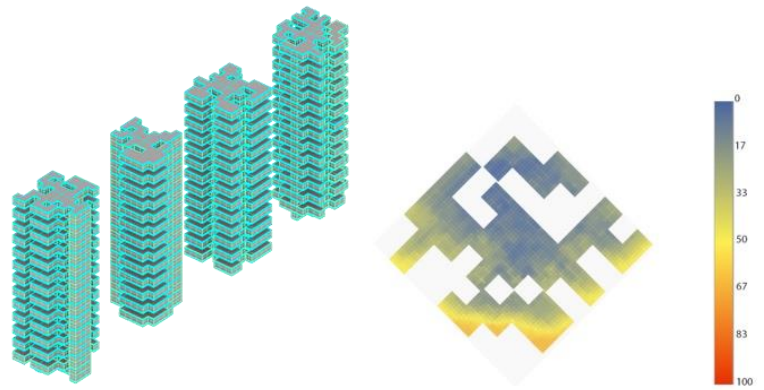

Figure 11: B2-1 Floor 8 and Floor South-East/SouthWest facing unit analysis using DIVA-for-Rhino. The analysis shows percentage of occupied hours that these nodes receive the target illuminance of 100 lux.

\section{Discussion}

As noted in the introduction, this speculative design study had a number of limitations because the complex variables of MURB design were not all taken into account. Building energy performance, structural efficiency, fire security, and economic viability are acknowledged as highly relevant issues in developing optimized design solutions for MURBs but in the interest of focusing on daylight, these aspects were not parametricized or evaluated in this study. Some of these variables could be taken into account in a further study. A more detailed study could take into account surrounding buildings, which would naturally impact the daylight in
Table 5: Option B2 Version 1 DIVA results.

\begin{tabular}{|l|l|l|}
\hline Floor & DA100lux [50\%] & Mean DA \\
\hline $\begin{array}{l}\text { Odd floors }(1,3,5, \\
7,9,11,13)\end{array}$ & $0 \%$ & $15 \%$ \\
\hline $\begin{array}{l}\text { Even floors }(2,4,6, \\
8,10,12,14,16,18, \\
20,22)\end{array}$ & $7 \%$ & $22 \%$ \\
\hline $\begin{array}{l}\text { Upper odd floors } \\
(15,17,1921,23)\end{array}$ & $0 \%$ & $16 \%$ \\
\hline Upper even floor 24, & $8 \%$ & $24 \%$ \\
\hline Top odd floor 25 & $0 \%$ & $19 \%$ \\
\hline Top even floor 26 & $16 \%$ & $34 \%$ \\
\hline
\end{tabular}

MURBs. Additionally, only one climate zone (Vancouver BC) and orientation (South-East/South-West) was tested and this could be expanded to compare to other building types and orientations. Larger questions of 'what is good daylight in MURBs' will be explored in future studies involving on site measurements and occupancy surveys to better explore what metrics, illuminance thresholds and environmental considerations impact daylight in MURBs.

\section{Conclusions}

This study focuses on daylight, yet there are a number of building performance aspects that need to be critically examined in order to design for quality of life in MURB. With so many variables, there are difficulties ininterpreting results due to conflicting findings. New studies investigate the need for new metrics specific to MURB, such as visual privacy (Alkalali et al, 2018), which examines the often conflicting desires for privacy inside the home and windows for views and daylight. Ventilation autonomy (Ko et al, 2018) is a metric that allows for the simultaneous assessment and visualization of ventilation, thermal and lighting comfort data in order to make it easier for designers to understand trade offs and benefits of design options.

Computational design tools offer great potentials for designing MURBs with better daylight. In particular, the use of a genetic algorithm to better understand complex variables and parametricize design aspects has been useful. While a GA should not guide the design of MURBs, GAs can uncover design opportunities and moments that can be further explored by the designer. In this paper, the intention was to explore generative design and climate-based daylight modelling as means of developing performance based and aesthetically interesting building forms that offer enhanced daylighting in MURBs. This paper identified the poor performance of typical MURBs for daylight, and proposed new techniques for form generation. A new workflow was developed and tested and a number of challenging issues have been identified. This section summarizes the interim conclusions stemming from the study underlying this paper.

Building Scale: The design of the building's geometry, in particular making the perimeter form more articulated, is 
shown to have a large impact on daylight in individual units. There is a need for more studies that experiment with the building's geometry for improved daylight in MURB units.

Metrics for Measuring Daylight: There is a need for better metrics for measuring daylight quality in MURBs. Spatial Daylight Autonomy was found to be useful when considered in relation to results from other metrics such as Mean Spatial Daylight Autonomy in order to enable comparison and interpretation of results. This conclusion supports earlier research by Peters and Kesik 2018.

Iterative Workflow: The generative design workflow developed and tested here of using a GA in Grasshopper and CBDM in Diva for Rhino tests these workflows for applicability as of an iterative design process. The fact that these tools are within the architect's design environments (Grasshopper and Rhino are increasily used by designers) shows promise that this workflow could be practical.

Unusual Spatial Qualities for MURBs: The generative design tool found spatial arrangements not normally seen in MURBs design. Double height spaces, courtyard outdoor spaces within the floorplate, and large outdoor terraces were all highly performing options for daylight. The outdoor qualities more closely match environmental characteristics found in other residential building types, giving the MURBs patios and front yards that may make them more desirable. The typical point tower base case MURB has low levels of spatial daylight autonomy (DA100lux [50\%]=2\%) and low mean spatial daylight autonomy (15\%) on all floors. All of the studies presented in this paper exceeded these levels in either DA or Mean DA

Daylight Proxy: The daylight proxy used in the GA based on Daylight Rule of Thumb worked well, and when compared to the DIVA analysis the best performing GA options were also highly performing for Mean Spatial Daylight Autonomy. The proposed generalized methodology could work with different proxys including climate and orientation.

Localized Optimization vs Building Optimization: A significant challenge in setting the parameters and interpreting the results of this study has been in the balancing design moves that contribute to localized optimization and those which contribute to overall building performance. For example, to make a suite daylit internal courtyards and outdoor terraces shape the floorplate but impact via overshading and preventing double height spaces on the floor below. could be tested in a future study. A follow up study will test where partition walls would go based on daylight as a spatial organizing feature; could consider outdoor spaces interior and exterior balconies; and could test optimizing for other climate zones.

\section{Acknowledgements}

The authors gratefully acknowledge the BC Housing Research Excellence Program for funding this project. Special thanks to our colleagues for sharing their knowledge and providing feedback on this paper and the underlying study.

\section{References}

Alkhalili, N., Kesik, T., O’Brien, W.O., Peters, T. (2018) Developing and testing visual privacy metrics. $7^{\text {th }}$ International Building Physics Conference IBPC 2018 Ithica (USA). September 23-26, 703-708.

Christodoulou, A., Vola, M., Rikken, G. Case Study for the Application of Multidisciplinary Computational Design Assessment and Constructability Optimisation Tools. SimAUD 2018, Delft, (Netherlands) 51-58.

DIVA. (2016). Version 4. Solemma LLC. Retrieved from http://solemma.net

Dogan, T and Park, Y.C. (2017). A new framework for residential daylight performance evaluation. Proceedings of Building Simulation 2017: The 15 th IBPSA Conference, San Francisco, (USA). August 79.

Dogan, T and Park, Y.C (2018) A critical review of daylighting metrics for residential architecture and a new metric for cold and temperate climates. Lighting Res. Technol. 2018; 0: 1-25.

Galasiu, A. and Reinhart, C. (2008). Current daylighting design practice: a survey. Building Research \& Information 36(2), 159-174.

Government of Canada, Canadian Census Data, (2016).

Herzog and de Meuron, "56 Leonard Street" https://www.herzogdemeuron.com/index/projects/co mplete-works/301-325/305-56-leonard-street.html Accessed 5 May 2018

Illuminating Engineering Society of North America, IESNA. (2012). LM-83-12 IES Spatial Daylight Autonomy (sDA) and Annual Sunlight Exposure (ASE). New York, NY, USA: IESNA Lighting Measurement.

Kesik T., \& O'Brien, L. Enhancing the livability and resilience of Multi-unit residential buildings (MURBs): MURB Design Guide, Version 1.0 January 2017.

https://www.daniels.utoronto.ca/faculty/kesik_t/MU RB-Design-Guide/MURB-Design-Guide-v1.0Jan2017.pdf

Ko, W.H., Schiavon, S., Brager, G., Levitt, B. Ventilation, thermal and luminous autonomy metrics for an intergrated design process. Building and Environment 145(2018) 153-165.

Peters T., \& Kesik T. (2018). Daylight Simulation for Multi-Unit Residentail Buildings: Occupant Centered Approaches to Assessment. eSim 2018. Montreal (Canada) May 9-10.

Reinhart, C.F., 2005. A simulation-based review of the ubiquitous window-head-height to daylit zone depth rule-of-thumb. Proceedings of Building Simulation 2005: The 9th International IBPSA Conference, Montreal (Canada) August 15-18, 1011-1018. 
Rutten, D. (2013). Galapagos on the Logic and Limitations of Generic Solvers. Architectural Design, March/April (222) 132-135.

Veitch, J., \& Galasiu A. (2012). The Physiological and Psychological Effects of Windows, Daylight, and View at Home: Review and Research Agenda. National Research Council of Canada Institute for Research in Construction NRC-IRC Research Report $R R-325$. 